\title{
Reuse of dewatered sewage sludge conditioned with skeleton builders as landfill cover material
}

\author{
Y. L. Li • J. W. Liu $\cdot$ J. Y. Chen · Y. F. Shi • \\ W. Mao $\cdot$ H. Liu $\cdot$ Y. Li $\cdot$ S. He $\cdot$ J. K. Yang
}

Received: 14 August 2012/Revised: 23 December 2012/ Accepted: 28 January 2013/Published online: 19 February 2013

(C) Islamic Azad University (IAU) 2013

\begin{abstract}
High water and organic content of sewage sludge constricts its reuse and disposal. It is often necessary to solidify/stabilize the dewatered sludge with solidifying agents before landfill disposal. In this study, the sewage sludge was conditioned with skeleton builders, i.e., fly ash and lime combined with ferric chloride for the purpose of improving the dewatering efficiency. The dewatered sewage sludge was then directly reused as landfill cover materials since the skeleton builders also play a role in solidification of sludge. The geotechnical properties of the dewatered sewage sludge were investigated. The results show that the plasticity index of the dewatered sludge increases compared to that of the dewatered sludge without any conditioner, and the permeability coefficient changes from $10^{-8}$ to $10^{-5} \mathrm{~cm} \mathrm{~s}^{-1}$. Furthermore, the strength of specimens increase with curing days. Microstructure analyses reveal that the main hydrated products are calcium silicate hydrate and ettringite, which contribute to the solidification/stabilization of the dewatered sludge. The results indicate that the dewatered sewage sludge conditioned with skeleton builders can be used as landfill covers. This study provides an alternative for traditional sewage sludge treatment and disposal.
\end{abstract}

\footnotetext{
Y. L. Li · J. W. Liu - J. Y. Chen · Y. F. Shi · W. Mao ·

H. Liu $\cdot$ J. K. Yang $(\bowtie)$

School of Environmental Science and Engineering,

Huazhong University of Science and Technology (HUST),

1037 Luoyu Road, Wuhan 430074, Hubei,

People's Republic of China

e-mail: jkyang@mail.hust.edu.cn

Y. Li $\cdot$ S. He

Universtar Science \& Technology (Shenzhen) Co., Ltd.,

Shenzhen 518057, People's Republic of China
}

Keywords Disposal - Geotechnical properties · Sludge dewatering $\cdot$ Solidification

\section{Introduction}

Municipal wastewater treatment typically generates sewage sludge as a by-product, which is difficult to dispose. In China, the annual sludge production has reached up to 24 million tons (dry wt) by 2010 (Zheng et al. 2011). Therefore, it is urgent to find an alternative to conventional sewage sludge disposal.

At present, three main approaches are being used for sewage sludge disposal in China: land application, landfill and incineration (Wang 1997), and landfill is the most common method (Zhu and Zhao 2011). However, sewage sludge usually has characteristics of high water content and low shear strength. The high water content makes it difficult to compact in landfill operation and causes a large amount of leachate. The low shear strength of sewage sludge may cause instability of slope and cell structure of landfills (Lo et al. 2002; Koenig et al. 1996).

Traditionally, the dewatered sludge cakes, conditioned with polyacrylamide (PAM), cannot meet the stringent landfill requirements. Consequently, solidifying agents are commonly added to achieve a high strength of solidified sludge. Table 1 summarizes the studies that use solidifying agents for solidification/stabilization of dewatered sludge in previous researches (Yin 2001; Lim et al. 2002; Lo et al. 2002; Kim et al. 2005; Tang et al. 2012). Yin (2001) investigated the geotechnical properties and behavior of local raw sludge mixed with pulverized fly ash (PFA) and lime. Lim et al. (2002) investigated modifiers such as hydrated lime, loess, and fly ash in the solidification/stabilization (S/S) of sewage sludge. Kim et al. (2005) 
investigated digested sewage sludge solidified with converter slag and quick lime as additives. Tang et al. (2012) used fly ash and lime as a stabilizer to stabilize lake sludge.

In addition, some researchers used other materials as solidifying agents. Wang et al. (2011) used stone material waste and Portland cement as solidifying agent for improving the strength of sludge. Zhen et al. (2012) investigated a calcined aluminum salts as solidifying agent to enhance the mechanical compressibility in order to make the landfill operation possible. Ma et al. (2010) investigated the sewage sludge solidified at variable proportions with magnesium oxychloride cement (denoted as MOC) as a solidifying agent. However, addition of solidifying agents into the dewatered sludge is likely to cause non-homogenous mixing, and excessive dosages of solidifying agents are often needed which causes higher treatment costs (Cinar et al. 2004).

The objective of this study was to develop an alternative for sewage sludge treatment which combines dewatering process with the following solidification procedure. The dewatered sludge was then reused as landfill covers. The new process in this study is compared with the traditional process, as shown in Fig. 1.
In traditional sewage sludge treatment, raw sludge was conditioned with PAM, and then the dewatered sludge, with a higher water content of about $80 \%$, was solidified with addition of solidification agents (Table 1). Sewage sludge produces highly compressible filter cakes that were difficult to be dewatered by pressure filtration because its particles would deform under high pressure (Zall et al. 1987). Physical conditioners, often known as skeleton builders, such as fly ash, lime, plaster, and cement were commonly used to enhance the rate and extent of sewage sludge dewatering (Liu et al. 2012; Qi et al. 2011; Chen et al. 2010; Zhao 2002) because they formed a permeable and rigid lattice structure in sludge cakes (Benítez et al. 1994).

In our previous studies, ferric chloride and common skeleton builders (lime and fly ash) were used as an inorganic composite conditioner to improve the dewatering performance of sewage sludge (Liang 2009; Liu et al. 2011a, b). An optimal mass ratio of fly ash: quicklime: ferric chloride in the composite conditioner was proposed as 1:1:0.3 in dewatering process. Under the optimum condition, the reduction ratio of specific resistance to filtration (SRF) reached over $93 \%$, and the water content of dewatered sludge cake was $55 \%$ (by wt). However, little

Table 1 Previous literatures of solidification/stabilization (S/S) of dewatered sludge

\begin{tabular}{|c|c|c|c|c|c|c|}
\hline \multirow[t]{2}{*}{ Researchers } & \multirow[t]{2}{*}{ Solidifying agents } & \multirow{2}{*}{$\begin{array}{l}\text { Dosage of } \\
\text { conditioners } \\
\text { (g/g dry sludge } \\
\text { solid) }\end{array}$} & \multicolumn{4}{|c|}{ Geotechnical properties of dewatered sewage sludge } \\
\hline & & & $\begin{array}{l}\text { Plasticity } \\
\text { index }\end{array}$ & $\begin{array}{l}\text { Permeability } \\
\text { coefficient } \\
\left(\mathrm{cm} \mathrm{s}^{-1}\right)\end{array}$ & $\begin{array}{l}\text { Compressive } \\
\text { strength }(\mathrm{kPa})\end{array}$ & $\begin{array}{l}\text { Shear strength } \\
(\mathrm{kPa})\end{array}$ \\
\hline Tang et al. (2012) & Fly ash and cement and lime & 1.00 & - & - & 620 & - \\
\hline Kim et al. (2005) & Quick lime and converter slag & 1.56 & 33.0 & $10^{-5}$ & 68.6 & - \\
\hline Lo et al. (2002) & Fly ash and hydrated lime & 2.10 & 10.7 & $10^{-4}$ & 157.9 & - \\
\hline Lim et al. (2002) & Fly ash and quick lime & 2.10 & - & $10^{-5}$ & 161.0 & - \\
\hline Yin (2001) & Fly ash and quick lime & 1.38 & 7.5 & - & 165.0 & 680 \\
\hline
\end{tabular}

- No report

Fig. 1 Schematic of the new process in this study compared with the traditional process
Traditional Process
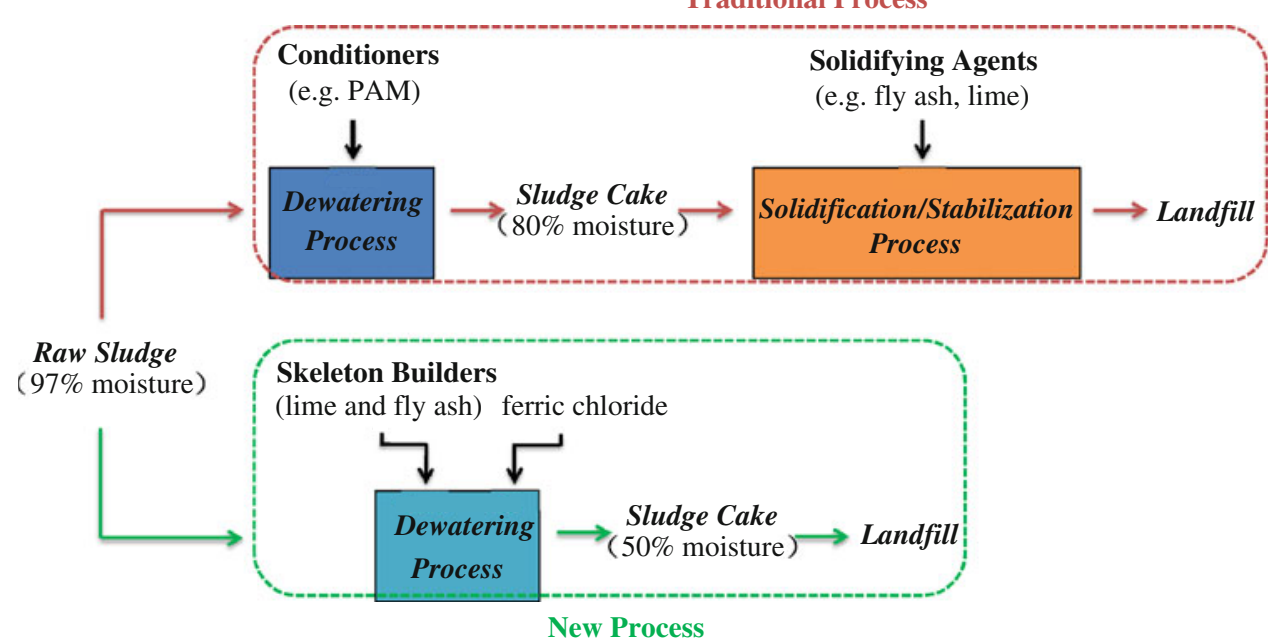
consideration was given to the effect of skeleton builders on the subsequent $\mathrm{S} / \mathrm{S}$ of dewatered sludge.

Based on the results of our previous studies, the inorganic composite conditioner was used in this study. Skeleton builders were added during the dewatering process so that they were homogeneously dispersed in the dewatered sludge. Instead of adding solidifying agents, the skeleton builders could also play a role in the subsequent $\mathrm{S} / \mathrm{S}$ stage for the dewatered sewage sludge. The geotechnical properties of the dewatered sewage sludge conditioned with the inorganic composite conditioner were investigated, and the feasibility of direct reutilization of the dewatered sludge as landfill cover material was also evaluated. The research was carried out from April 2011 to July 2011 in the School of Environmental Science and Engineering, Huazhong University of Science and Technology (HUST), Wuhan City, China.

\section{Materials and methods}

\section{Raw sewage sludge}

The raw sewage sludge used in the study was a mixture of primary and secondary sludge from Longwangzui wastewater treatment plant in Wuhan, China. The capacity of this municipal wastewater treatment plant is $150,000 \mathrm{~m}^{3} \mathrm{~d}^{-1}$, and it employs an anaerobic-anoxic-oxic process. The raw sewage sludge was obtained in April. Raw sludge samples were collected in polypropylene containers and stored at $4{ }^{\circ} \mathrm{C}$ in a refrigerator. Raw sludge was used in the dewatering experiments during 2 days.

The raw sludge was dried at $105{ }^{\circ} \mathrm{C}$ for $24 \mathrm{~h}$ to determine its solid content. The characteristics of raw sludge were tested according to the standard methods (US EPA 1995). The results are shown in Table 2.

Table 3 presents the results of the X-ray fluorescence (XRF, PANalytical B.V., Netherlands) tests of the dried raw sewage sludge sample.
The main inorganic elements in the dried raw sewage sludge are $\mathrm{Si}, \mathrm{Al}, \mathrm{P}$, and $\mathrm{Ca}$, as shown in Table 3. The loss on ignition (LOI) of the sewage sludge is $50.99 \%$, which is consistent with the VSS/SS ratio in Table 2. It indicates that organic matters in the dried raw sewage sludge are more than $50 \%$ (by wt.).

Inorganic conditioners

In this study, skeleton builders (fly ash and quicklime) and ferric chloride were used as inorganic conditioners. Fly ash was obtained from a coal-combustion power plant in Henan province, China. The major compositions of fly ash are $\mathrm{SiO}_{2}\left(60.35\right.$ wt \%) and $\mathrm{Al}_{2} \mathrm{O}_{3}(29.40$ wt \%). Quicklime used in this study was passed through a screen of $0.5 \mathrm{~mm}$, and the content of free- $\mathrm{CaO}$ was above $60 \%$. Ferric chloride of industrial grade was provided by Baililian Chemical Limited Company in Henan Province, China.

\section{Dewatering process}

The dewatering process employed in this study is shown in Fig. 2. It comprises three stages: sludge conditioning, sludge feeding, and diaphragm filter presses.

First, raw sewage sludge was slowly pumped in a $35-\mathrm{L}$ tank from polypropylene containers, and then mixed at $300 \mathrm{rpm}$ for $1 \mathrm{~min}$. After that sludge was conditioned with the inorganic composite conditioners at $50 \mathrm{rpm}$ for $30 \mathrm{~min}$. The conditioned sludge was then fed into a $25-\mathrm{L}$ feeding tank by a screw pump. To feed sludge into the diaphragm filter press, step pressure was carried out from 0 to $0.8 \mathrm{MPa}$ by an air compressor. The sludge dewatering process was continued under a pressure of $0.8 \mathrm{MPa}$ for $30 \mathrm{~min}$. After the sludge cake was formed, the diaphragm located at the top of each chamber was inflated by the air compressor, thus reducing the chamber volume and squeezing the cakes further to remove water from the sludge cakes. Finally, the dewatered sludge cakes were collected at the end of the dewatering process.

Table 2 Characteristics of raw sewage sludge

\begin{tabular}{lllllll}
\hline Parameters & Moisture (\%) & $\mathrm{pH}$ & $\mathrm{COD}\left(\mathrm{mg} \mathrm{L}^{-1}\right)$ & $\mathrm{SCOD}\left(\mathrm{mg} \mathrm{L}^{-1}\right)$ & $\mathrm{VSS} / \mathrm{SS}(\%)$ & $\begin{array}{l}\text { Specific resistance to } \\
\text { filtration }(\mathrm{SRF})\left(\times 10^{9} \mathrm{~S}^{2} \mathrm{~g}^{-1}\right)\end{array}$ \\
\hline Raw sludge & $97.1 \pm 2.7$ & $6.71 \pm 0.23$ & $24,000 \pm 100$ & $432 \pm 12$ & $50.75 \pm 7.52$ & $2.37 \pm 0.37$ \\
\hline
\end{tabular}

Table 3 Main inorganic chemical compositions of dried raw sewage sludge (wt \%)

\begin{tabular}{lllllllllllll}
\hline Constituents & $\mathrm{Na}_{2} \mathrm{O}$ & $\mathrm{MgO}$ & $\mathrm{Al}_{2} \mathrm{O}_{3}$ & $\mathrm{SiO}_{2}$ & $\mathrm{P}_{2} \mathrm{O}_{5}$ & $\mathrm{SO}_{3}$ & $\mathrm{~K}_{2} \mathrm{O}$ & $\mathrm{CaO}$ & $\mathrm{Fe}_{2} \mathrm{O}_{3}$ & $\mathrm{Cl}$ & $\mathrm{Others}^{2}$ & $\mathrm{LOI}^{\mathrm{a}}$ \\
\hline Percentage & 0.38 & 0.96 & 11.62 & 23.10 & 4.49 & 1.48 & 0.97 & 2.13 & 3.08 & 0.14 & 0.68 & 50.99 \\
\hline
\end{tabular}

a LOI means loss on ignition at $1,200^{\circ} \mathrm{C}$ 
Fig. 2 Process flow diagram of dewatering

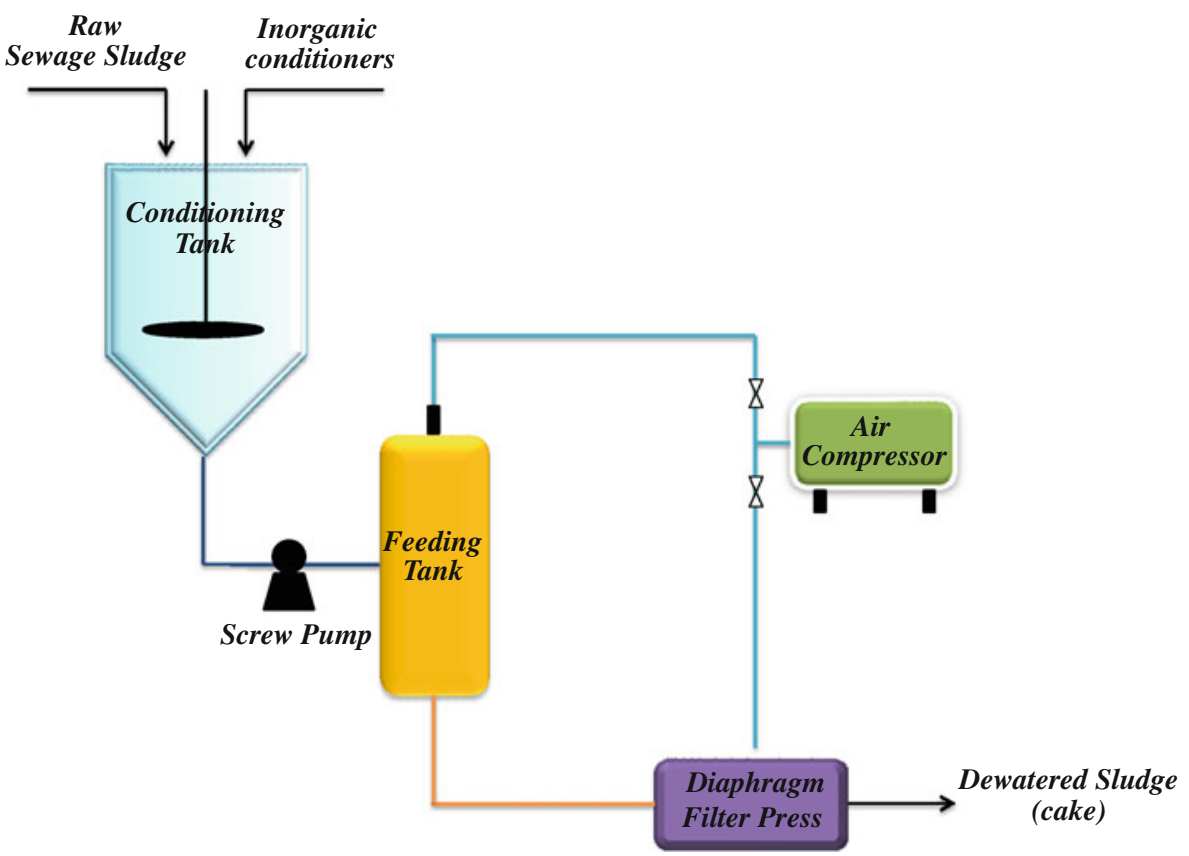

Geotechnical properties of the solidified sludge specimens

The specimen was molded in a self-made compactor device to determine the maximum dry density and the corresponding optimum moisture content. The cylindrical specimen in the unconfined compressive test was $3.91 \mathrm{~cm}$ in diameter and $8.0 \mathrm{~cm}$ in length. The cylindrical specimen in the direct shear test was $6.18 \mathrm{~cm}$ in diameter and $2.0 \mathrm{~cm}$ in length. The specimens were cured in a curing facility at $(20 \pm 2){ }^{\circ} \mathrm{C}$ with humidity above $90 \%$ for different curing days. Each group consisted of six specimens. Three specimens were used to evaluate the mechanical strength after lying immersed in water for $24 \mathrm{~h}$, referred as the wet-saturated specimens. Other three cured specimens were directly used to evaluate the mechanical strength, referred as the dry specimens. The main mechanical strength properties, i.e., unconfined compressive strength and shear strength, were tested according to standard soil laboratory test methods (Head 1992). Several other geotechnical properties of the dewatered sludge were also investigated, including water content, critical water content, compaction and penetration. Once placed in landfills, the treated sludge was considered as a geotechnical material. To evaluate the effects of the lime-fly ash admixture on the physical properties of the dewatered sludge, the liquid limit and plastic limit were also determined under ambient condition according to ASTM D4318 (ASTM 2010).

Microstructural analysis

Microstructural characteristics of dewatered sewage sludge samples cured for different days were investigated by
X-ray diffraction (XRD) and scanning electron microscope (SEM) technologies. The samples were collected from the broken wet-saturated specimens after the unconfined compressive tests. These samples were immersed in ethanol for $24 \mathrm{~h}$ to end hydration reaction. Subsequently, the samples were dried in an oven at $40^{\circ} \mathrm{C}$. XRD analysis were carried out using $\mathrm{Cu} \mathrm{K} \alpha$, operated at $40 \mathrm{kV}$, with a scan speed of $0.2785^{\circ} \%$ and in the $2 \theta$ range from $5^{\circ}$ to $75^{\circ}$. Morphology studies were carried out with a Sirion 200 scanning microscope after the samples were coated with gold.

\section{Results and discussion}

Dewatering results and sludge characteristics

To evaluate the geotechnical properties of the dewatered sewage sludge, experiments were designed and conducted with different dosages of inorganic composite conditioners. The related conditioning and dewatering procedures were followed by the previous study (Liu et al. 2011a, b). The results are shown in Table 4.

As shown in Table 4, the moisture content of the sludge cake decreases with an increased dosage on conditioners since skeleton builders are kept in the dewatered sludge cake. Meanwhile, compared to the dewatered sludge without skeleton builders (D-0), the dewatered sewage sludge samples conditioned with skeleton builders has a large plastic index and larger permeability for the reason that the skeleton builders can form a permeable and rigid lattice structure in the dewatered sludge (Zall et al. 1987). 
Table 4 Geotechnical properties of dewatered sewage sludge

\begin{tabular}{lllllll}
\hline No. & $\begin{array}{l}\text { Dosage of } \\
\text { conditioners } \\
(\mathrm{g} / \mathrm{g} \text { dry sludge })\end{array}$ & $\begin{array}{l}\text { Water content of } \\
\text { sludge cake }(\%)\end{array}$ & $\begin{array}{l}\text { Optimum water } \\
\text { content }(\%)\end{array}$ & $\begin{array}{l}\text { Maximum dry } \\
\text { density }\left(\mathrm{g} \mathrm{cm}^{-3}\right)\end{array}$ & $\begin{array}{l}\text { Plasticity } \\
\text { index }\end{array}$ & $\begin{array}{l}\text { Permeability coefficient } \\
\left(\mathrm{cm} \mathrm{s}^{-1}\right)\end{array}$ \\
\hline D-0 & 0.0 & $88.3 \pm 2.1$ & $60.1 \pm 1.5$ & $1.432 \pm 0.03$ & $14.1 \pm 0.5$ & $(6.85 \pm 0.15) \times 10^{-8}$ \\
D-1 & 0.8 & $71.0 \pm 1.4$ & $29.6 \pm 2.0$ & $1.142 \pm 0.05$ & $28.9 \pm 0.3$ & $(6.59 \pm 0.12) \times 10^{-6}$ \\
D-2 & 1.0 & $66.9 \pm 3.1$ & $34.7 \pm 0.4$ & $1.157 \pm 0.10$ & $28.7 \pm 0.1$ & $(6.63 \pm 0.21) \times 10^{-6}$ \\
D-3 & 1.5 & $63.5 \pm 1.7$ & $34.5 \pm 0.5$ & $1.173 \pm 0.04$ & $33.3 \pm 1.7$ & $(6.68 \pm 0.17) \times 10^{-6}$ \\
D-4 & 2.0 & $51.2 \pm 2.3$ & $34.7 \pm 2.3$ & $1.178 \pm 0.05$ & $36.7 \pm 1.9$ & $(6.56 \pm 0.45) \times 10^{-6}$ \\
D-5 & 3.0 & $45.9 \pm 1.6$ & $32.5 \pm 2.4$ & $1.186 \pm 0.07$ & $42.0 \pm 2.5$ & $(4.67 \pm 0.05) \times 10^{-6}$ \\
\hline
\end{tabular}

a The mass ratio of fly ash:quicklime:ferric chloride was 1:1:0.3 in inorganic conditioners

Permeability coefficient of municipal solid waste usually ranged from $1.0 \times 10^{-5}$ to $1.0 \times 10^{-2} \mathrm{~cm} \mathrm{~s}^{-1}$ (McBean et al. 1995). Kim et al. (2005) used converter slag and quick lime as solidifying agents for solidification of digested sewage sludge. In their study, the permeability coefficients ranged from 3.7 to $5.9 \times 10^{-5} \mathrm{~cm} \mathrm{~s}^{-1}$. By comparing permeability coefficient in Table 4 with that in Table 1, it can be seen that the dewatered sludge in this study has lower permeability coefficient $\left(\sim 10^{-6} \mathrm{~cm} \mathrm{~s}^{-1}\right)$ than that of the stabilized sewage sludge in previous studies $\left(\sim 10^{-5} \mathrm{~cm} \mathrm{~s}^{-1}\right)$. Heavy metals and organic matters can transfer from solidified/ stabilized sludge into leachate in landfill environment (Zhu et al. 2006). In this study, the risk of heavy metals and organic matters entering into leachate becomes low because of lower permeability coefficient.

From geotechnical properties shown in Table 4, most indexes of geotechnical properties of dewatered sewage have not changed significantly at various conditioner dosages of $0.8,1.0,1.5,2.0,3.0 \mathrm{~g} / \mathrm{g}$ dry sludge, respectively, i.e. permeability coefficient, plasticity index, maximum dry density, and optimum water content. However, water content of dewatered sludge cake has decreased significantly from $71.0 \pm 1.4$ to $45.9 \pm 1.6 \%$ when dosage of conditioners increases from 0.8 to $3.0 \mathrm{~g} / \mathrm{g}$ dry sludge. In new Chinese standard for the run of municipal waste water treatment plant, the maximum limit of water content of dewatered sludge is $60 \%$ (MOHURD 2007). And thus, optimum dosage of conditioners is $2.0 \mathrm{~g} / \mathrm{g}$ dry sludge used in the following geotechnical tests. (No. D-4 in Table 4).

\section{Unconfined compressive strength test}

Unconfined compressive strength was chosen as one of the main variables for predicting the structural suitability and durability on utilization or disposal of dewatered sludge in landfill. It can also be thought of as an indicator of whether hydration reactions take place (Stegemann and Buenfeld 2003; Taha et al. 2010). The relationship between unconfined compressive strengths and curing days is shown in Fig. 3.
As shown in Fig. 3, the unconfined compressive strength of the specimens increases with an increase of curing days. It can be attributed to the addition of skeleton builders that improve the geotechnical properties of the treated sewage sludge. The improvement in strength of the dewatered sewage sludge specimens is due to the hydration products generated from fly ash and lime. The hydration reaction takes place when fly ash is mixed with lime in the moist environment. The active silica and active alumina in fly ash can react with lime, and the corresponding hydration product is the calcium silicate hydrate $(\mathrm{C}-\mathrm{S}-\mathrm{H})$. These hydrated products grow gradually and fill up the voids in the specimen (Soliman 1990). During the hydration, the water in the sludge was absorbed, and the organic particles of the sludge were surrounded by the skeleton builders, which improved the strength.

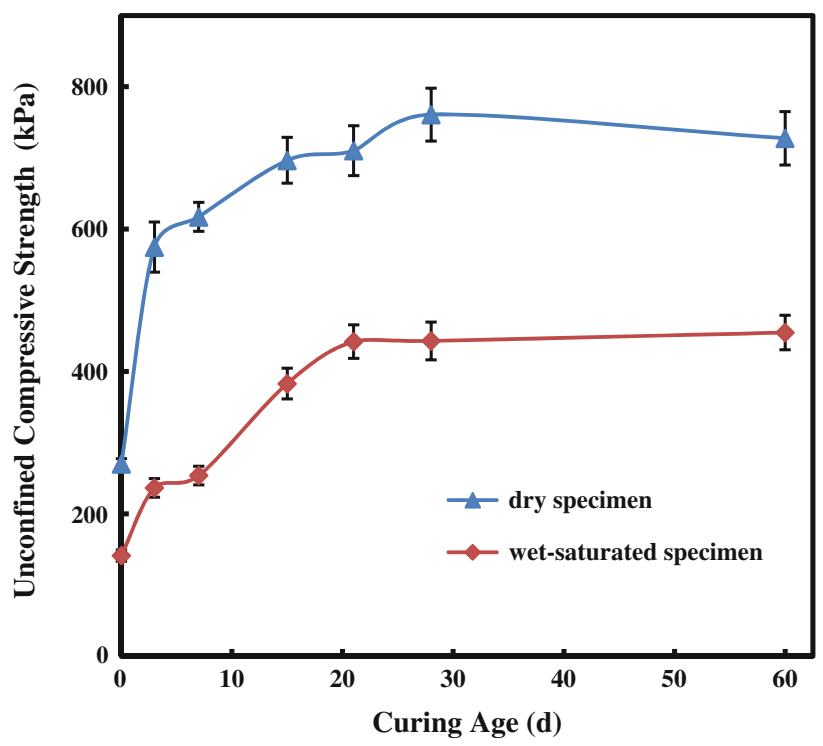

Fig. 3 Unconfined compressive strengths of dewatered sewage sludge samples cured for various days 


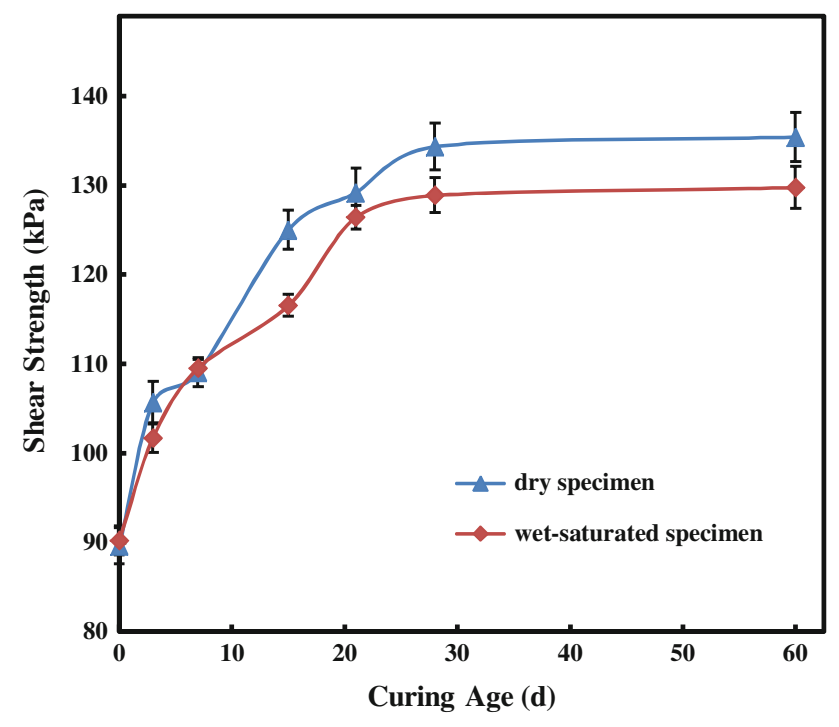

Fig. 4 Shear strengths of dewatered sewage sludge samples cured for various days

Shear strength test

The shear strength of the dewatered sludge is required for the assessment of slope stability in landfill (Zhan et al. 2008). The shear strengths of the dewatered sewage sludge samples cured for various days under a vertical load of $200 \mathrm{kPa}$ are shown in Fig. 4. The shear strengths of the specimens increase with an increase in curing days.

The shear strengths of the specimens after the wetsaturated immersion are lower than those of the dry specimens with the same curing time. Nevertheless, the shear strength loss after wet-saturated immersion is $<10 \%$, which could meet the requirement for a typical landfill environment.

\section{Microstructure characteristics}

$\mathrm{X}$-ray diffraction patterns were investigated on the specimens of the dewatered sludge after various curing days (Fig. 5).

The results indicate that the content of $\mathrm{Ca}(\mathrm{OH})_{2}$ decreases with an increase in curing days. The ettringite (AFt) forms after specimens have cured for 21 days. The hydrated products of the pozzolanic process are generally considered to be $\mathrm{C}-\mathrm{S}-\mathrm{H}$, which contributes to the increase of strength of the specimens. Some $\mathrm{C}-\mathrm{S}-\mathrm{H}$ exist as amorphous (Chen et al. 2004), and some peaks of C-S-H crystalline phases could easily be overlapped by peaks of other phases when the amount of $\mathrm{C}-\mathrm{S}-\mathrm{H}$ is lower. And thus, diffraction peaks of $\mathrm{C}-\mathrm{S}-\mathrm{H}$ could not be identified in the XRD patterns of Fig. 5.

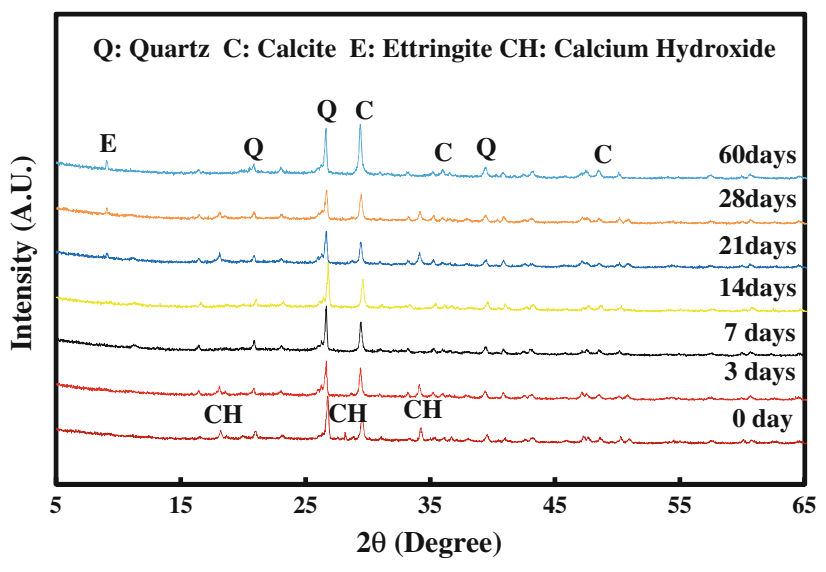

Fig. 5 XRD patterns of specimens of the dewatered sludge cured for different days

In this study, an admixture was used as stabilizers to improve dewater ability, since the admixture contained $\mathrm{SiO}_{2}$ and $\mathrm{Al}_{2} \mathrm{O}_{3}$, and possessed the properties of pozzolana. It also improved the engineering characteristics of the raw sludge. Figure 6 displays the results of the SEM images of different specimens.

As shown in Fig. 6a, the dewatered sludge (D-0) is dense since many organic matters exist in the raw sludge that fills most of voids in the dried raw sludge sample. Poorly filterable sludge needs to be conditioned with skeleton building solids to produce a more porous and incompressible cake structure needed for successful filter pressing. As shown in Fig. 6b, dewatered sludge conditioned with skeleton builders is more porous in the dried dewatered sludge sample (D-4). It indicates that poorly dewater able sludge with high organic content can be conditioned with skeleton builders to produce a more porous and incompressible cake structure. As shown in Fig. $6 \mathrm{c}$ and d, many significant hydrated products generate in the specimens at 28 and 60 curing days. In the cured specimens, the needle-shaped crystals and honeycombshaped hydrated products, the typical morphologies of Aft and C-S-H compounds (Taylor 1990), are observed at the surface of the dewatered sludge made from skeleton builders (Fig. 6c, d).

During the early stage of curing, the mechanical strengths of the specimens are lower, as the shown in Figures 3 and 4. The initial strength comes from mechanical compaction. The pozzolanic reaction in fly ash is typically much slower than that in the ordinary Portland cement (OPC). As the curing time increases, pozzolanic reactions between fly ash and lime take place, and the hydration products are formed as shown in Eqs. (1)-(3) (Yang et al. 2008). 



Fig. 6 SEM images for dewatered sludge cake and specimens made from dewatered sludge cured for different days: a dewatered sludge cake of D-0, b dewatered sludge cake of D-4, $\mathbf{c}$ the broken specimens

$$
\begin{aligned}
& \mathrm{SiO}_{2}+x \mathrm{Ca}(\mathrm{OH})_{2}+m \mathrm{H}_{2} \mathrm{O} \rightarrow x \mathrm{CaO} \cdot \mathrm{SiO}_{2} \cdot n \mathrm{H}_{2} \mathrm{O} \\
& \mathrm{Al}_{2} \mathrm{O}_{3}+x \mathrm{Ca}(\mathrm{OH})_{2}+m \mathrm{H}_{2} \mathrm{O} \rightarrow x \mathrm{CaO} \cdot \mathrm{Al}_{2} \mathrm{O}_{3} \cdot n \mathrm{H}_{2} \mathrm{O} \\
& \\
& \quad 6 \mathrm{Ca}^{2+}+2 \mathrm{AlO}_{2}^{-}+3 \mathrm{SO}_{4}^{2-}+4 \mathrm{OH}+29 \mathrm{H}_{2} \mathrm{O} \\
& \quad \rightarrow \mathrm{Ca}_{6} \mathrm{Al}_{2}\left(\mathrm{SO}_{4}\right)_{3}(\mathrm{OH})_{12} \cdot 26 \mathrm{H}_{2} \mathrm{O}
\end{aligned}
$$

The formation of ettringite and $\mathrm{C}-\mathrm{S}-\mathrm{H}$ accelerates the pozzolanic reaction of fly ash, which contributes to longterm strengths of the cured specimens.

\section{Conclusion}

In this paper, lime and fly ash were utilized as skeleton builders to improve sludge dewatering. Meanwhile, the skeleton builders were also served as stabilizers to improve the geological properties of the dewatered sludge. The current study could provide evidence for
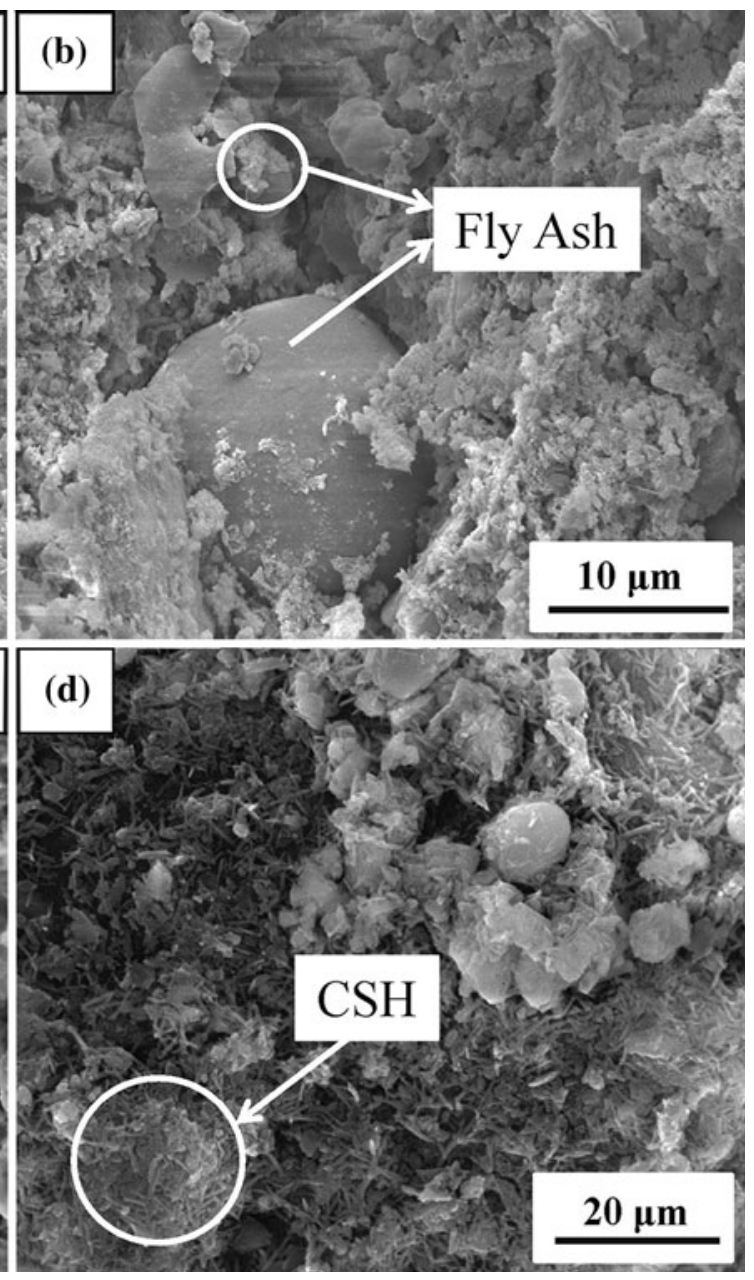

cured for 28 days after the unconfined compressive test, and $\mathbf{d}$ the broken specimens cured for 60 days after the unconfined compressive test

combining sludge dewatering process with sludge disposal. Moreover, the geotechnical properties in this study can meet the requirements for landfill covers without any other additives, and this study provides an alternative for traditional sewage sludge treatment and disposal. Besides being used as landfill cover material, dewatered sewage sludge conditioned with skeleton builders might be used in other potential applications, such as in mining site reclamation engineering, and in construction and building industry.

As a result, the permeability coefficient of dewatered sludge $\left(\sim 10^{-6} \mathrm{~cm} \mathrm{~s}^{-1}\right)$ in this study is lower than that of stabilized sewage sludge in other previous literatures $\left(\sim 10^{-5} \mathrm{~cm} \mathrm{~s}^{-1}\right)$. The risk of heavy metals and organic matters entering into leachate becomes low because of lower permeability coefficient. The unconfined compressive strength and the shear strength increase with the increasing curing days, which complied with the requirements of landfill disposal. The XRD patterns and SEM 
images show that the strengths of specimens are mainly attributed from the hydrated products, i.e., ettringite and amorphous $\mathrm{C}-\mathrm{S}-\mathrm{H}$, which are formed from the pozzolanic reaction with the skeleton builders.

Acknowledgments The authors would like to express their gratitude to the financial supports from the National Natural Science Foundation of China (51078162), New Century Excellent Talents Project of the Ministry of Education (NCET-09-0392), the Special Fund (2011TS123) and Wuhan Municipal Natural Science Foundation (201260723226). They would also like to thank the Analytical and Testing Center of the Huazhong University of Science \& Technology, which supplied the facilities for the experiments.

\section{References}

ASTM (2010) Standard test method for liquid limit, plastic limit and plasticity index of soils. (ASTM D4318-10) American Society for Testing and Materials, Conshohocken, pp 3-12

Benítez J, Rodriguez A, Suárez A (1994) Optimization technique for sewage sludge conditioning with polymer and skeleton builders. Water Res 28(10):2067-2073

Chen JJ, Thomas JJ, Taylor HFW, Jennings HM (2004) Solubility and structure of calcium silicate hydrate. Cement Concrete Res 34(9):1499-1519

Chen C, Zhang P, Zeng G, Deng J, Zhou Y, Lu H (2010) Sewage sludge conditioning with coal fly ash modified by sulfuric acid. Chem Eng J 158(3):616-622

Cinar S, Onay TT, Erdinçler A (2004) Co-disposal alternatives of various municipal wastewater treatment-plant sludges with refuse. Adv Environ Res 8(3):477-482

Head KH (1992) Manual of soil laboratory testing, vol. 1, Soil Classification and Compaction Test, 2nd edn, Pentech Press, London, pp 78-115

Kim EH, Cho JK, Yim S (2005) Digested sewage sludge solidification by converter slag for landfill cover. Chemosphere 59(3):387-395

Koenig A, Kay JN, Wan IM (1996) Physical properties of dewatered wastewater sludge for landfilling. Water Sci Technol 34(3-4): $533-540$

Liang M (2009) The study on the sludge dewatering based on skeleton builder and the durability of bricks from sewage sludge. Master thesis, Huazhong University of Science \& Technology, pp 17-33 (in Chinese)

Lim S, Jeon W, Lee J, Lee K, Kim N (2002) Engineering properties of water/wastewater-treatment sludge modified by hydrated lime, fly ash and loess. Water Res 36(17):4177-4184

Liu H, Li Y, Shi YF, Li Y, He S, Yang JK (2011a) Influence of inorganic composite conditioner on dewatering performance of sewage sludge. Environ Chem 30(11):1877-1882 (in Chinese)

Liu H, Yang JK, Shi YF, Li Y, He S (2011b) Relationship of evaluation indexes of sludge dewatering performance under different conditioning programs. Environ Sci 32(11):3394-3399 (in Chinese)

Liu H, Yang J, Shi Y, Li Y, He S, Yang C, Yao H (2012) Conditioning of sewage sludge by Fenton's reagent combined with skeleton builders. Chemosphere 88(2):235-239

Lo IMC, Zhou W, Lee K (2002) Geotechnical characterization of dewatered sewage sludge for landfill disposal. Can Geotech J 39(5):1139-1149
Ma JL, Zhao YC, Wang JM, Wang L (2010) Effect of magnesium oxychloride cement on stabilization/solidification of sewage sludge. Constr Build Mater 24(1):79-83

McBean EA, Rovers FA, Farquahar GJ (1995) Solid waste landfill; engineering and design. Prentice Hall, Englewood Cliffs, p 501

MOHURD (2007) The disposal of sludge from municipal wastewater treatment plant-Sludge quality for co-landfilling. (CJ/T 249-2007) Ministry of Housing and Urban-Rural Development. Beijing, China, $\mathrm{p} 2$

Qi Y, Thapa KB, Hoadley AFA (2011) Application of filtration aids for improving sludge dewatering properties-A review. Chem Eng J 171(2):373-384

Soliman NN (1990) Laboratory testing of lime fixed flyash and FGD sludge. ASTM Special Technical Publication, Philadelphia, pp 168-183

Stegemann J, Buenfeld N (2003) Prediction of unconfined compressive strength of cement paste containing industrial wastes. Waste Manage 23(4):321-332

Taha RA, Mohamedzein YEA, Al-Rawas AA, Al-Suleimani Y (2010) Solidification of tank bottom sludge. Geotech Geol Engineering 28(1): $15-25$

Tang H, Li X, Li M, Song L, Wu Z, Xu H (2012) Properties and mechanism of CFBC fly ash-cement based stabilizers for lake sludge. J Wuhan Univ Technol-Mater Sci Ed 27(4):750-753

Taylor HFW (1990) Cement Chemistry. Academic Press, London, pp $180-182$

US EPA (1995) Test methods for evaluating solid waste: Physical/ chemical methods (3rd ed). US Environmental Protection Agency, Washington, pp 2-7

Wang MJ (1997) Land application of sewage sludge in China. Sci Total Environ 197(1):149-160

Wang YX, Ding JW, Hong ZS (2011) Compressive strength characteristics and volume change of sewage sludge matrices solidified by a new binder. Adv Mater Res 255:2819-2823

Yang M, Qian JS, Pang Y (2008) Activation of fly ash-lime systems using calcined phosphogypsum. Constr Build Mater 22(5):10041008

Yin JH (2001) Properties and behavior of raw sludge mixed with pulverized fuel ash and lime. Geotech Test J 24(3):299-307

Zall J, Galil N, Rehbun M (1987) Skeleton builders for conditioning oily sludge. Water Pollut Control Fed 59(7):699-706

Zhan TLT, Chen Y, Ling W (2008) Shear strength characterization of municipal solid waste at the Suzhou landfill China. Eng Geol 97(3):97-111

Zhao YQ (2002) Enhancement of alum sludge dewatering capacity by using gypsum as skeleton builder. Colloids Surf A Physicochem Eng Asp 211(2):205-212

Zhen GY, Lu XQ, Cheng XB, Chen H, Yan XF, Zhao YC (2012) Hydration process of the aluminate $12 \mathrm{CaO} \cdot 7 \mathrm{Al}_{2} \mathrm{O}_{3}$-assisted Portland cement-based solidification/stabilization of sewage sludge. Constr Build Mater 30:675-681

Zheng GY, Yan XF, Zhou HY, Chen H, Zhao TT, Zhao YC (2011) Effects of calcined aluminum salts on the advanced dewatering and solidification/stabilization of sewage sludge. J Environ Sci 23(7):1225-1232

Zhu Y, Zhao YC (2011) Stabilization process within a sewage sludge landfill determined through both particle size distribution and content of humic substances as well as by FT-IR analysis. Waste Manage Res 29(4):379-385

Zhu W, Li L, Lin C (2006) Biochemical effects on permeability of solidified sludge. Rock Soil Mech 27(6):933-938 (in Chinese) 